23

\title{
Оптические свойства растворенного органического вещества поверхностного слоя воды моря Лаптевых
}

\author{
(c) А.Н. Дроздова \\ Институт океанологии им. П.П. Ширшова РАН, \\ 117997 Москва, Россия \\ e-mail: adrozdova@ocean.ru
}

Поступила в редакцию 22.10.2018 г.

В окончательной редакции 19.11.2018 г.

Принята к публикации 04.12.2018 г.

Рассмотрены особенности флуоресценции гуминовых соединений, выносимых со стоком реки Лена в сентябре 2015 г. Показано изменение оптических свойств растворенного органического вещества, а именно спектров флуоресценции и коэффициентов поглощения при длине волны $350 \mathrm{~nm}$ на разрезе от дельты реки Лена к континентальному склону. Для гуминовых соединений терригенного происхождения определено положение максимума флуоресценции при длинах волн возбуждения 270, 310 и $355 \mathrm{~nm}$. Показано распространение пресных речных вод реки Лена на протяжении всего шельфа, причем гуминовые соединения являются главной составляющей окрашенной фракции растворенного органического вещества. В пробах, отобранных у континентального склона, зафиксировано присутствие лабильного автохтонного органического вещества. Содержание растворенного органического вещества в речной воде в 2015 году сопоставимо с результатами предыдущих исследований, и составило $548 \mu \mathrm{M} / \mathrm{L}$.

DOI: $10.21883 /$ OS.2019.03.47382.309-18

\section{Введение}

Растворенное органическое вещество (РОВ) природного происхождения является одним из наиболее важных компонентов морских экосистем, играющих ключевую роль в глобальном цикле углерода [1]. В арктическом бассейне резервуар РОВ оценивается в работе [2] как $9 \cdot 10^{12} \mathrm{~kg}$ углерода. По причине труднодоступности судьба терригенного РОВ в зонах смешения река-море в шельфовых морях арктического региона и в центральном арктическом бассейне остается неясной $[3,4]$. Поскольку Арктика во многом определяет климат на Земле и при этом наиболее чувствительна к его изменениям [5], наблюдаемое в последнее время таяние богатой органическим веществом вечной мерзлоты несет значительные экологические риски [6]. В связи с этим регулярные наблюдения районов арктического шельфа и Северного Ледовитого океана, наиболее подверженных влиянию пресных вод, идентификация пресных вод в арктическом бассейне, имеют исключительную ценность.

В последнее время широкое развитие при изучении происхождения и динамики РОВ получили оптические методы [7], прежде всего флуоресцентная и абсорбционная молекулярная спектроскопия окрашенной фракции в УФ и видимом диапазонах. Окрашенное РОВ включает в себя белки и ароматические аминокислоты (прежде всего триптофана [8]), нуклеиновые кислоты, фенолы и полифенольные соединения (лигнин, танин), гуминовые соединения, а также некоторые пигменты [9]. Состав и соотношение этих компонентов индивидуально для каждой акватории, и поэтому „оптические маркеры“ успешно используются для идентификации природных вод и изучения процессов деградации РОВ. Кроме того, определение оптических свойств морской среды и речных вод необходимо для определения РОВ методами дистанционного зондирования.

Целью представленной работы было изучение поглощения при $350 \mathrm{~nm}$ и флуоресценции РОВ опресненного поверхностного слоя воды моря Лаптевых, а также их взаимосвязи с содержанием растворенного органического углерода (РОУ).

\section{Материалы и методы}

Пробы воды были отобраны в 63-м рейсе НИС „Академик Мстислав Келдыш“ в период с 8 по 11 сентября 2015 г. на 12 станциях, расположенных вдоль $130^{\circ} \mathrm{E}$, рис. 1. При движении от дельты реки Лена к континентальному склону соленость в поверхностном слое менялась от 3 до 30. Воду фильтровали через мембранный фильтр с условным диаметром пор $0.7 \mu \mathrm{m}$.

Оптические свойства РОВ. Воду анализировали на борту судна сразу после фильтрации. Регистрация трехмерных спектров флуоресценции выполнена на спектрофлуориметре „Флюорат-02-Панорама“ фирмы „Люмэкс“, длина кюветы $1 \mathrm{~cm}$, в диапазоне длин волн от 240 до $650 \mathrm{~nm}$ с шагом $1 \mathrm{~nm}$, при варьировании длины волны возбуждения от 230 до $550 \mathrm{~nm} \mathrm{с} \mathrm{шагом} 5 \mathrm{~nm}$. С точки зрения оценки содержания РОУ наиболее перспективной характеристикой окрашенной фракции РОВ в настоящее время считается коэффициент поглощения при длине волны $350 \mathrm{~nm}, a_{350}[10]$, рассчитываемый на основании спектров поглощения $A(\lambda)$ согласно следующему соот- 


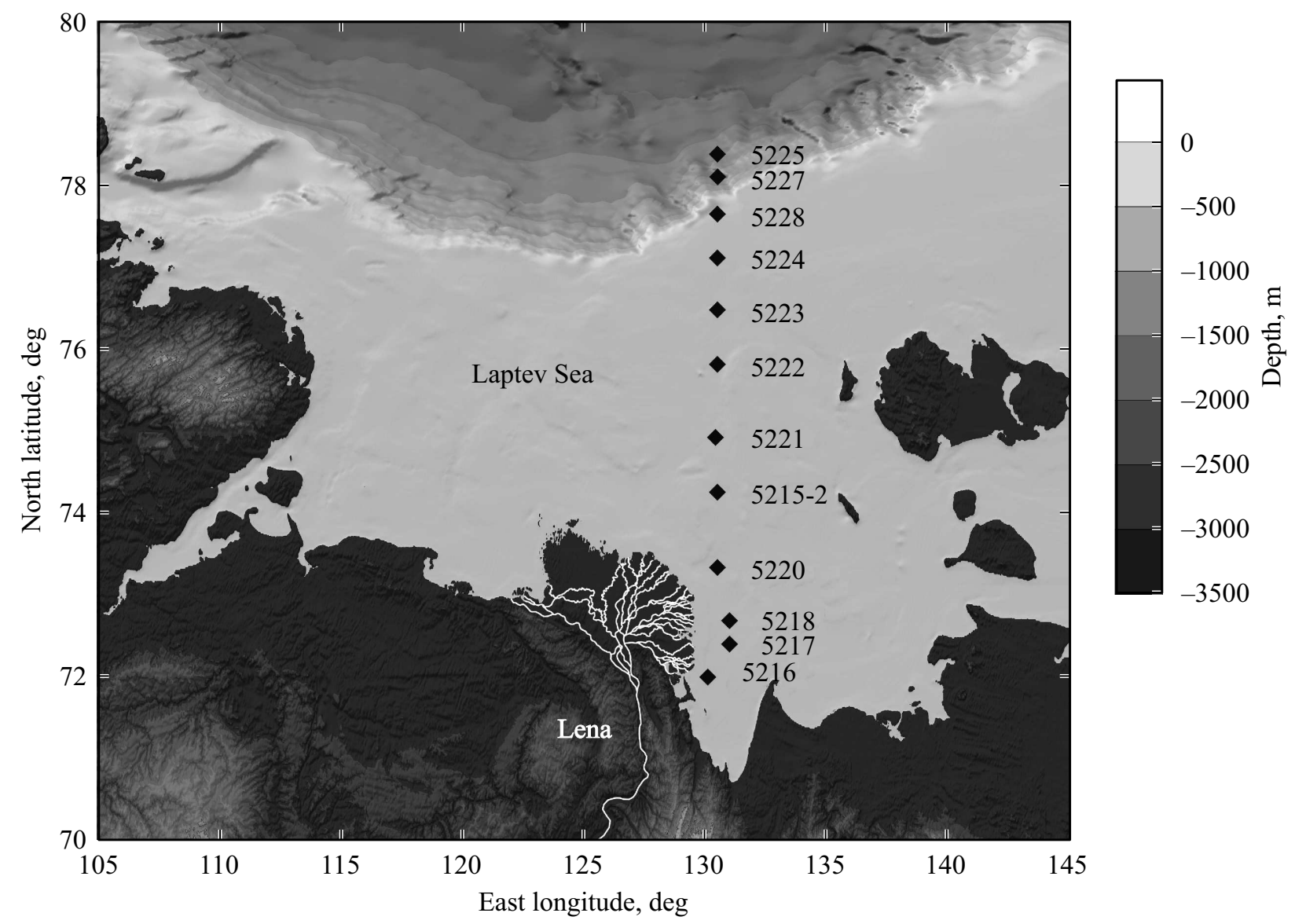

Рис. 1. Расположение станций на разрезе в море Лаптевых, где отбирались пробы в 63-м рейсе НИС „Академик Мстислав Келдыш“.

ношению:

$$
a_{\lambda}=A(\lambda) \cdot 2.303 / l
$$

где $l$ - длина кюветы, m. В настоящей работе для оценки перспектив использования зависимости РОУ $\left(a_{350}\right)$ для экспрессного определения РОУ в море Лаптевых в осенний период были использованы значения $a_{350}$, опубликованные в работе [11].

Содержсание растворенного органического углерода (РОУ). Для определения содержания РОУ фильтрат подкисляли соляной кислотой до $\mathrm{pH}=2$ и хранили в стеклянных виалах при температуре $2-3^{\circ} \mathrm{C}$ до последующего анализа в лаборатории ИО РАН. Концентрацию РОУ определяли методом высокотемпературного сжигания на анализаторе углерода Shimadzu TOC Vcph. Погрешность прибора 1\%. Воспроизводимость результатов анализа $\pm 5 \%$.

\section{Результаты исследования и обсуждение}

Концентрация РОУ в исследуемых образцах менялась в диапазоне от $497 \mu \mathrm{M} / \mathrm{L}$ на станции 5216 (дельта реки Лена, соленость 3.0) до $193 \mu \mathrm{M} / \mathrm{L}$ на станции 5225 (континентальный склон, глубина $2800 \mathrm{~m}$, соленость 30.1).
При этом выявлен консервативный характер распределения растворенного органического углерода, о чем свидетельствует линейная зависимость содержания РОУ от солености морской воды, описывающаяся следующим уравнением: РОУ $=548-10.5 \cdot$ соленость, $R^{2}=0.88$. Исключением является проба со станции 5227, для которой концентрация РОУ максимальна и составила $540 \mu \mathrm{M} / \mathrm{L}$. Предполагая консервативное распределение РОВ в пограничной зоне река-море при значениях солености от 0 до 3.0, концентрацию РОУ в р. Лена можно оценить как $548 \mu \mathrm{M} / \mathrm{L}$, что хорошо согласуется с результатами предыдущих исследований, представленными в работах $[3,12](506-1050 \mu \mathrm{M} / \mathrm{L})$.

Зависимость концентрации РОУ от коэффициента поглощения на длине волны $350 \mathrm{~nm}$ приведена на рис. 2. Для поверхностных вод моря Лаптевых наблюдается хорошая корреляция между этими показателями морской воды, что позволяет использовать $a_{350}$ для экспрессной оценки содержания РОУ для поверхностных вод исследуемого региона, подверженных значительному влиянию пресных вод. Полученная в настоящей работе прямая заметно отличается от универсальной зависимости (рис. 2, штриховая линия), полученной для проб воды, отобранных в 2004 и 2005 гг. вблизи устьев рек Обь, 


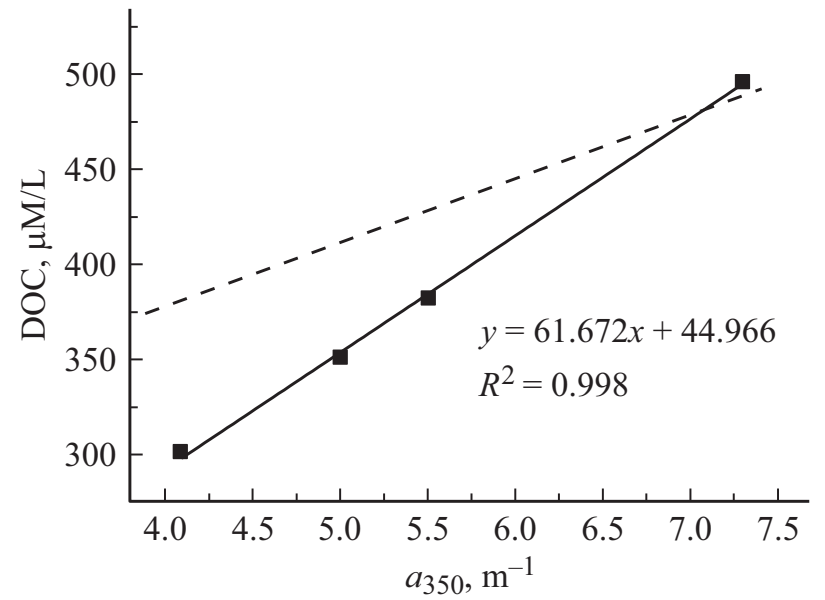

Рис. 2. Зависимость содержания растворенного органического углерода от коэффициента поглощения на длине волны $350 \mathrm{~nm}$. Штриховой линией показана аналогичная зависимость, полученная в работе [10] для РОВ рек Обь, Енисей, Лена, Колыма и Маккензи.

Оптические характеристики флуорофоров по данным [14]

\begin{tabular}{|c|c|c|}
\hline Флуорофор & $\begin{array}{c}\text { Длина волны } \\
\text { возбуждения, } \\
\text { nm }\end{array}$ & $\begin{array}{c}\text { Максимум } \\
\text { флуоресценции, } \\
\mathrm{nm}\end{array}$ \\
\hline Гуминовые соединения & $237-260$ & $400-500$ \\
\hline Гуминовые соединения & $300-370$ & $400-500$ \\
\hline $\begin{array}{c}\text { Белковые соединения } \\
\text { (триптофан) }\end{array}$ & 275 & 340 \\
\hline $\begin{array}{c}\text { Белковые соединения } \\
\text { (тирозин) }\end{array}$ & 275 & 305 \\
\hline
\end{tabular}

Енисей, Лена, Колыма и Маккензи. Погрешность при использовании универсальной зависимости для определения РОУ по коэффициенту поглощения $a_{350}$ превысит $25 \%$ при коэффициентах поглощения ниже $4.2 \mathrm{~m}^{-1}$. Это может быть связано как с изменением свойств речной воды, так и с активными процессами преобразования органического вещества в пограничной зоне река-море вблизи устьев рек. Следовательно, в акваториях, характеризующихся влиянием небольшого числа источников опреснения, таких как Карское море, море Лаптевых и др., необходимо изучать оптические свойства РОВ для получения актуальных данных, необходимых при использовании космической съемки и методов дистанционного зондирования природных вод.

Типичный спектр флуоресценции РОВ состоит из двух перекрывающихся полос - УФ полосы с максимумом в области $300-350 \mathrm{~nm}$ (флуоресценция остатков ароматических аминокислот) и свечения в видимой области спектра с максимумом 400-450 nm (флуоресценция гуминовых соединений) (таблица).

На рис. 3 приведены спектры флуоресценции воды со станции 5216 при длинах волн возбуждения 270, 310 и $355 \mathrm{~nm}$. Флуоресценция в коротковолновой обла- сти спектра, соответствующая белковым соединениям, отсутствует, в то время как флуоресценция гуминовых соединений, содержащихся в речной воде, хорошо выражена. На этом примере видно, что максимум свечения гуминовых соединений зависит от длины волны возбуждения - при изменении длины волны возбуждения от 270 до $310 \mathrm{~nm}$ максимум полосы испускания смещается в сторону более коротких длин волн. Дальнейшее увеличение длины волны возбуждения приводит к смещению максимума флуоресценции в длинноволновую область. Такое спектральное поведение выделяет РОВ среди других органических люминофоров [9].

По мере удаления от дельты реки Лена интенсивность флуоресценции в области $400-500 \mathrm{~nm}$ уменьшается, что объясняется перемешиванием речных и морских вод. На станция 5225, расположенной на границе шельфа, флуоресценция речного органического вещества в спек-

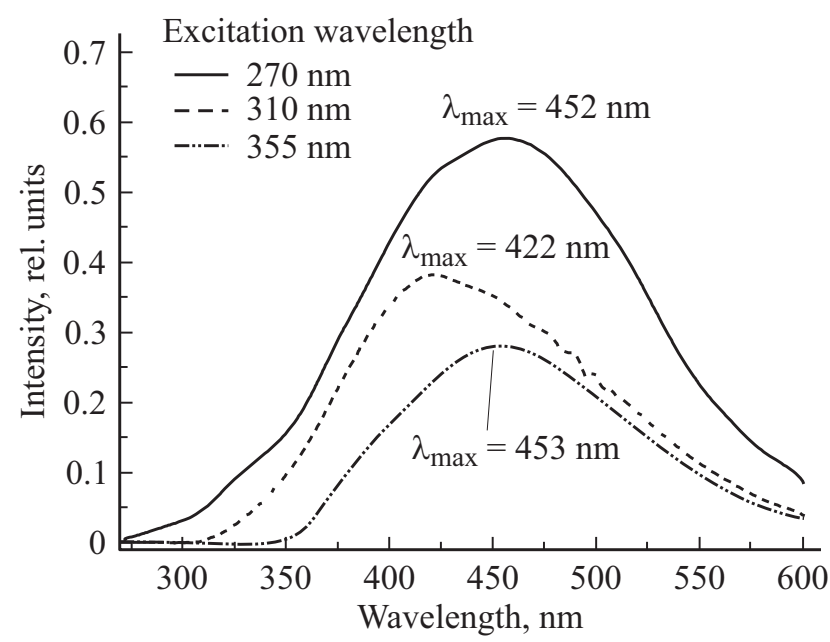

Рис. 3. Спектры флуоресценции пробы воды (станция 5216), характеризующейся минимальным значением солености (3.0), при длинах волн возбуждения 270, 310 и $355 \mathrm{~nm}$.

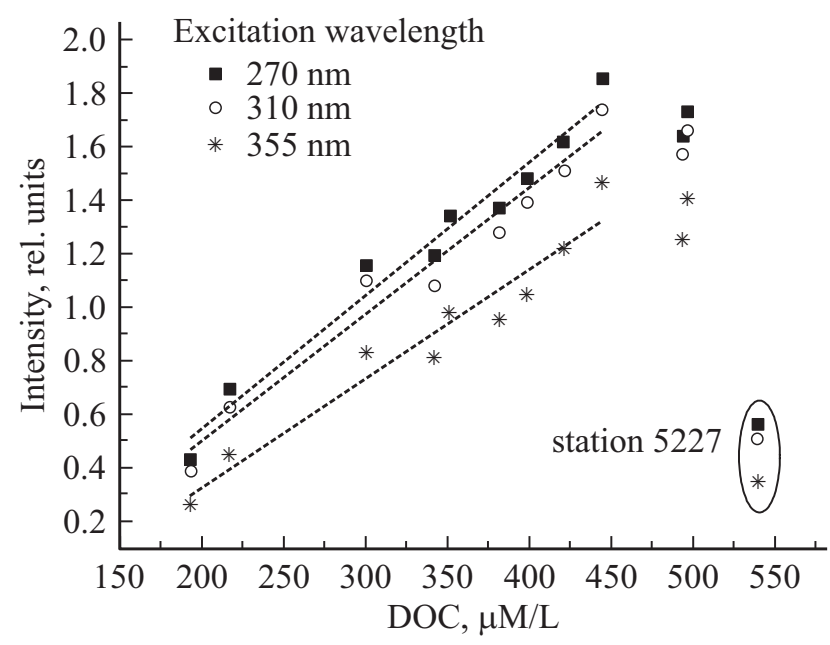

Рис. 4. Зависимость интенсивности флуоресценции гуминовых соединений в области 400-500 nm от содержания РОУ для различных длин волн возбуждения. 


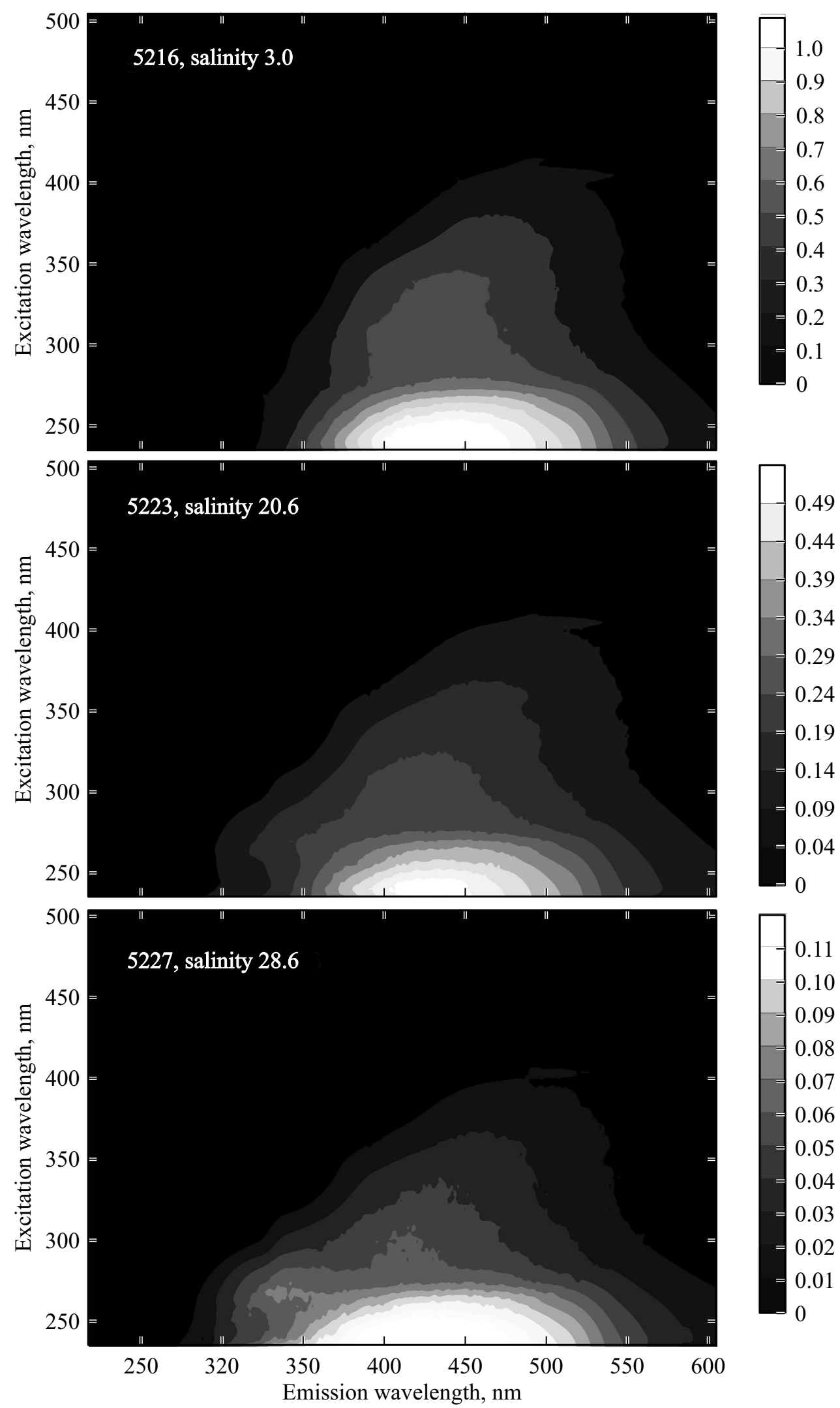

Рис. 5. Зависимость интенсивности флуоресценции от длин волн возбуждения и испускания. 


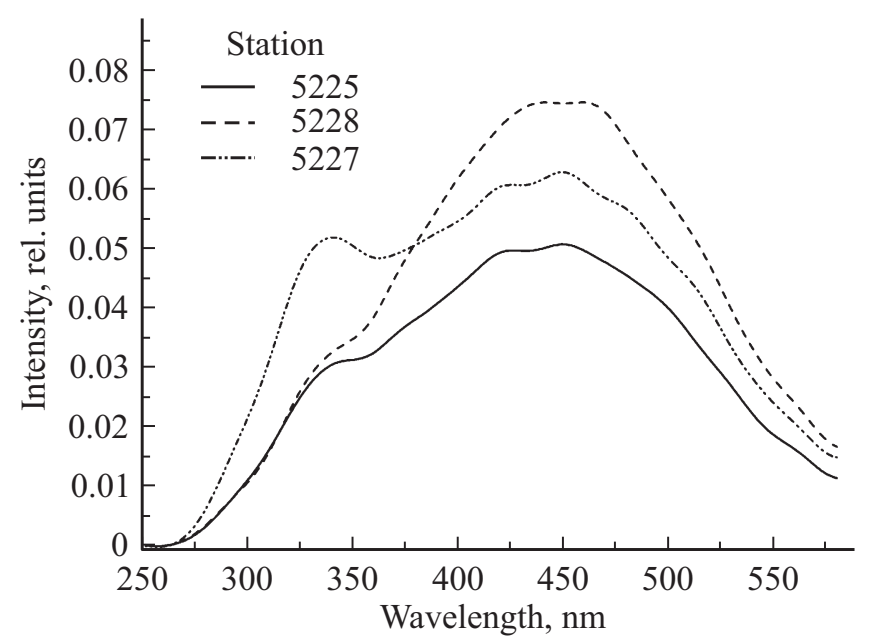

Рис. 6. Флуоресценция РОВ при длине волны возбуждения $270 \mathrm{~nm}$ на 3-х соседних станциях в области континентального склона в море Лаптевых.

тре флуоресценции РОВ слабо выражена. На рис. 4 представлены зависимости интенсивности флуоресценции гуминовых соединений от содержания РОУ. Линейная зависимость для трех представленных на рисунке длин волн наблюдалась для диапазона концентраций $193-445 \mu \mathrm{M} / \mathrm{L}$ или $2.32-5.34 \mathrm{mg} / \mathrm{L}$. Величина $R^{2}$ составила $0.967,0.954$ и 0.930 для длин волн возбуждения 270,310 и $355 \mathrm{~nm}$ соответственно. Уменьшение интенсивности флуоресценции в диапазоне $400-500 \mathrm{~nm}$ для проб морской воды с содержанием РОУ $493.6 \mu \mathrm{M} / \mathrm{L}$ (станция 5222) и $496.8 \mu \mathrm{M} / \mathrm{L}$ (станция 5216) по сравнению со станцией 5218, где содержание РОУ составило $444.8 \mu \mathrm{M} / \mathrm{L}$, связано, по-видимому, с концентрационным тушением флуоресценции и/или эффектом внутреннего фильтра. Исследование РОВ шведских озер показало, что эффект внутреннего фильтра необходимо учитывать для природных вод, содержание РОУ в которых превышает $175 \mu \mathrm{M} / \mathrm{L}$. При этом необходимо принимать во внимание, что эффект внутреннего фильтра сказывается в первую очередь на интенсивности флуоресценции, возбуждаемой на коротких длинах волн, поскольку поглощение природных вод монотонно убывает с увеличением длины волны [13].

На рис. 5 приведены трехмерные спектры флуоресценции (зависимости интенсивности флуоресценции от длин волн возбуждения и испускания) РОВ со станций 5216, 5223 и 5227. Эти данные наглядно демонстрируют увеличение доли автохтонного органического вещества, максимумы поглощения и испускания которого находятся в диапазонах $270-280 \mathrm{~nm}$ и $350-360 \mathrm{~nm}$ соответственно.

Отдельно следует отметить станцию 5227, на которой наблюдается повышенное содержание РОУ в поверхностном слое воды. На этой станции флуоресценция в области $350-360 \mathrm{~nm}$ сопоставима по интенсивности c флуоресценцией гуминовых соединений и примерно в два раза превышает интенсивность флуоресценции в этой области спектра для проб с соседних станций 5228 и 5225 , рис. 6 . Таким образом, повышенное содержание РОУ, вероятно, обусловлено автохтонной составляющей РОВ.

\section{Выводы}

Показано, что коэффициент поглощения $a_{350}$ может быть использован для экспрессной оценки содержания РОУ в поверхностном слое воды моря Лаптевых. Рассмотрены особенности флуоресценции гуминовых соединений терригенного происхождения, выносимых со стоком реки Лена. Положение максимума полосы флуоресценции зависит от длины волны возбуждения и варьируется в диапазоне от 422 до $453 \mathrm{~nm}$. Линейная зависимость интенсивности флуоресценции при длинах волн испускания выше $420 \mathrm{~nm}$ нарушается при концентрациях РОУ выше $445 \mu \mathrm{M} / \mathrm{L}$ или $5.34 \mathrm{mg} / \mathrm{L}$.

Характер флуоресценции РОВ на разрезе „Дельта реки Лена-континентальный склон“ указывает на распространение пресных речных вод в поверхностном слое на протяжении всего шельфа моря Лаптевых в сентябре 2015 г. При этом гуминовые соединения являются доминирующей составляющей РОВ. В пробах, отобранных у границы шельфа, зафиксировано присутствие лабильного автохтонного органического вещества с повышенным его содержанием на станции 5227.

Поскольку в условиях изменения климата большой интерес представляет сезонная и межгодовая динамика изменения спектров поглощения и флуоресценции РОВ, в дальнейшем планируется отбор и изучение оптических свойств поверхностного слоя воды моря Лаптевых и их сравнение с полученными в данной работе результатами.

Изучение оптических свойств РОВ моря Лаптевых выполнено при поддержке РФФИ, грант № 16-35-60032 мол_а_дк. Анализ спектров флуоресценции для выявления флуорофоров, присутствующих в Арктических морях, выполнен при поддержке гранта РНФ № 18-7700053.

\section{Список литературы}

[1] Романкевич Е.А., Ветров А.А., Пересыпкин В.И. Органическая геохимия океана / Мировой океан. Физика, химия и биология океана. Осадкообразование в океане и взаимодействие геосфер Земли. Т. 2. / Под. ред. Нигматулина Р.И., Лобковского Л.И. М.: Науч. мир, 2013. С. 130.

[2] Mcguire A., Anderson L., Christensen T., Scott D., Laodong G., Hayes D., Martin H., Lorenson T., Macdonald R., Nigel R. // Ecol. Monogr. 2009. V. 79. № 4. P. 523. doi 10.1890/08-2025.1

[3] Amon R.M.W. The role of dissolved organic matter for the organic carbon cycle in the Arctic Ocean / The Organic Carbon Cycle in the Arctic Ocean / Eds. Stein R.S., Macdonald R.W. Berlin: Springer, 2004. P. 83. 
[4] Gonçalves-Araujo R., Stedmon C.A., Heim B., Dubinenkov I., Kraberg A., Moiseev D., Bracher A. // Front. Mar. Sci. 2015. V. 2. N 108. doi 10.3389/fmars.2015.00108

[5] Kostianoy A.G., Nihoul J.C. Frontal Zones in the Norwegian, Greenland, Barents and Bering Seas. Influence of climate change on the changing Arctic and sub-Arctic conditions. Netherlands: Springer, 2009. P. 171.

[6] Frey K.E., McClelland J.W. // Hydrol. Process. 2009. V. 23. P. 169. doi 10.1002/hyp.7196

[7] Stedmo C.A., Nelson N.B. The optical properties of DOM in the ocean. Biogeochemistry of Marine Dissolved Organic Matter, 2nd edn. / Eds. Hansell D.A., Carlson C.A. Cambridge, MA: Academic Press, 2014. P. 509.

[8] Тен Г.Н., Глухова О.Е., Слепченков М.М., Щербакова Н.Е., Баранов В.И. // Опт. и спектр. 2016. Т. 121. № 4. C. 655; Ten G.N., Glukhova O.E., Slepchenkov M.M., Shcherbakova N.E., Baranov V.I. // Opt. Spectrosc. 2016. V. 121. N 4. P. 599. doi 10.1134/S0030400X16100246

[9] Горшкова О.М., Пацаева С.В. // Вода. Хим. и экол. 2009. № 11 . C. 31.

[10] Walker S.A., Amon R.M.W., Stedmon C.A. // J. Geophys. Res. Biogeosci. 2013. V. 118. N 4. P. 1689. doi 10.1002/2013jg002320

[11] Drozdova A.N., Kravchishina M.D., Khundzhua D.A., Freidkin M.P., Patsaeva S.V. // Int. J. Remote Sens. 2018. P. 1 (in press). doi 10.1080/01431161.2018.1506187

[12] Stedmon C.A., Amon R.M.W., Rinehart A.J., Walker S.A. // Mar. Chem. 2011. V. 124. P. 108. doi 10.1016/j.marchem.2010.12.007

[13] Kothawala D.N., Murphy K.R., Stedmon C.A., Weyhenmeyer G.A., Tranvik L.J. // Limnol. Oceanogr. Methods. 2013. V. 11. P. 616. doi 10.4319/1om.2013.11.616

[14] Hudson N., Baker A., Reynolds D. // River Res. Appl. 2007. V. 23. N 6. P. 631. doi 10.1002/rra.1005 